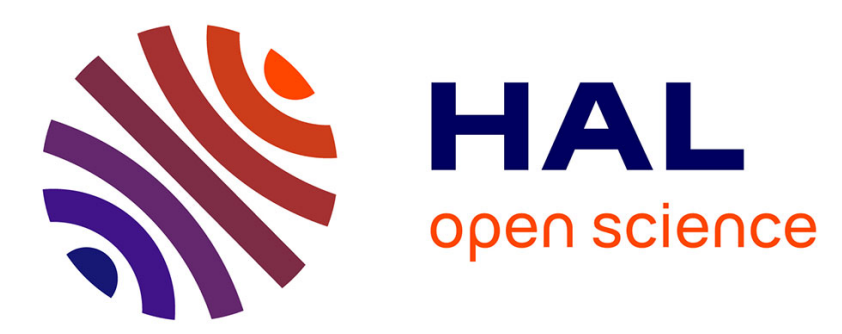

\title{
Frailty, polypharmacy, and potentially inappropriate medications in old people: findings in a representative sample of the French population
}

\author{
Marie Herr, Nicolas Sirven, Hélène Grondin, Sylvain Pichetti, Catherine
}

Sermet

\section{To cite this version:}

Marie Herr, Nicolas Sirven, Hélène Grondin, Sylvain Pichetti, Catherine Sermet. Frailty, polypharmacy, and potentially inappropriate medications in old people: findings in a representative sample of the French population: Medication prescribing, and frailty. European Journal of Clinical Pharmacology, 2017, 73 (9), pp.1165 - 1172. 10.1007/s00228-017-2276-5 . inserm-01802861

\section{HAL Id: inserm-01802861 https://www.hal.inserm.fr/inserm-01802861}

Submitted on 29 May 2018

HAL is a multi-disciplinary open access archive for the deposit and dissemination of scientific research documents, whether they are published or not. The documents may come from teaching and research institutions in France or abroad, or from public or private research centers.
L'archive ouverte pluridisciplinaire HAL, est destinée au dépôt et à la diffusion de documents scientifiques de niveau recherche, publiés ou non, émanant des établissements d'enseignement et de recherche français ou étrangers, des laboratoires publics ou privés. 


\section{Frailty, polypharmacy and potentially inappropriate medications in old people: findings in a representative sample of the French population}

Marie HERR ${ }^{1,2}$, Nicolas SIRVEN ${ }^{3,4}$, Hélène GRONDIN ${ }^{1}$, Sylvain PICHETTI ${ }^{3}$, Catherine SERMET $^{3}$

${ }^{1}$ UMR 1168, Vieillissement et Maladies chroniques : approches épidémiologique et de santé publique, INSERM and Université Versailles St-Quentin-en-Yvelines, Villejuif \& Montigny-le-Bretonneux, France

${ }^{2}$ Centre de Gérontologie, Hôpital Sainte-Périne, Assistance Publique-Hôpitaux de Paris, France

${ }^{3}$ Institut de recherche et documentation en économie de la santé (IRDES)

${ }^{4}$ LIRAES, Université Paris Descartes

Running title: Medication prescribing, and frailty

Conflict of interest: none to declare

Word count for the abstract: 258

Word count for the text: 2864

Number of figures: 1

Number of tables: 3

Number of appendix: 3 


\section{Abstract}

Purpose: This study analyses the relationship between medication use and frailty by considering the quantity of medications prescribed (polypharmacy) and the quality of medication prescribing (according to French criteria for Potentially Inappropriate Medications - PIMs) in people aged 65 and over.

Methods: This is a cross-sectional study based on the data from a nationally representative study about health and use of healthcare resources in France (ESPS 2012). The number of frailty criteria was assessed among exhaustion, unintentional weight loss, muscle weakness, impaired mobility, and low level of physical activity. Polypharmacy and PIMs were assessed from the data of reimbursement by the National Health Insurance over the whole year 2012. PIMs were defined according to the Laroche list plus additional criteria dealing with inappropriate prolonged use of medications. The analyses used Poisson regression models, with the number of frailty criteria as dependent variable.

Results: The study population was composed of 1003 women and 887 men, of mean age $74.7+/-$ 7.4 years. Polypharmacy (5 to 9 drugs) and excessive polypharmacy ( $\geq 10$ drugs) were reported in $42.9 \%$ and $27.4 \%$ of the study population respectively, while $46.7 \%$ of the study population received at least one PIM during the year 2012. Polypharmacy and PIMs were both associated with the number of frailty criteria in models adjusted for socio-demographic and health characteristics of the participants. The prescription of anticholinergic medications was the only PIM that remained significantly associated with the number of frailty criteria after adjustment for polypharmacy.

Conclusions: Polypharmacy and use of anticholinergic medications are independently associated with frailty in old people. 
Key words: aged; anticholinergic medications; frailty; inappropriate prescribing; polypharmacy 


\section{$\underline{\text { Introduction }}$}

Frailty is defined as an increased vulnerability to stressors, resulting from a decrease in physiological reserves of multiple systems. It has been operationalized as a phenotype, determined by the presence of a critical number of impairments in physical strength, physical activity, nutrition, mobility and energy [1]. Epidemiological studies have shown that frailty is associated with a higher use of healthcare resources $[2,3]$ and predicts health outcomes such as occurrence or aggravation of functional limitations, falls, hospitalisations, and mortality $[4,5]$.

The concept of frailty is now well recognized by geriatricians and prevention stakeholders. Primary care physicians are encouraged to screen their patients for frailty and to address them when necessary to day hospitals where an evaluation of the causes of frailty will lead to a personalized care plan [6]. The reduction of polypharmacy is part of the intervention to manage frailty.

Epidemiological studies have shown that frail people are more likely to receive polypharmacy compared to non-frail individuals [7-11]. Polypharmacy exposes old people to various risks [12], notably adverse drugs events [13], falls [14], increased use of healthcare services, and mortality $[15,16]$. Polypharmacy also increases the risk of receiving "potentially inappropriate medications" (PIMs), i.e. medications with a well-established risk of adverse effect in old people or medications with questionable efficacy. The first set of explicit criteria for PIMs was developed in 1991 by Beers et al to be used in nursing homes [17] and has since been updated several times and adapted in different countries.

In this context, this study aimed to analyse the relationship between medication use and frailty by considering the quantity of medications prescribed (polypharmacy) and the quality of medication prescribing (according to French criteria for PIMs) in people aged 65 and over participating in a 
nationally representative study about health and use of healthcare resources in France where data about frailty and medications were thoroughly assessed.

\section{Methods}

\section{Study design and population}

We used cross-sectional data from the 2012 French health, health care, and insurance survey (Enquête sur la santé et la protection sociale, ESPS) matched with National Health Insurance data. The survey, coordinated by the Institute for Research and Information in Health Economics (IRDES, Paris), was designed to be representative of the French population (1 individual included in ESPS being representative of 2231 individuals on average in general population). The source population consisted of the 599,544 individuals included in the EGB (Echantillon Généraliste des Bénéficiaires) in 2012, a permanent representative sample of the population covered by the French public health insurance. A random subsample of community-dwellers was drawn from the EGB; these reference individuals together with members of their household were eligible for the survey. A total of 8413 households representing 23,047 French residents took part in the 2012 survey. Among them, $14.2 \%$ were 65 years old or more (3271 observations remaining). Survey respondents were then matched with National Health Insurance data (in the EGB) for 1955 observations. Unmatched individuals were those household members whose public health insurance was independent from the reference individual's health insurance known in the EGB. An additional 65 observations were discarded because we did not have information about medications for these individuals. Our analysis sample eventually consisted in 1890 communitydwellers aged 65 and over. 


\section{Data collection}

Participants were first interviewed by telephone (or directly at home for people who did not have the telephone or for whom the telephone number was wrong) about the socio-demographic characteristics of their household. Information about their health status, access to health care services, health insurance, and the economic and social status of individuals were then collected by using self-administered questionnaires. Participants gave their informed consent and ESPS received the approval of the National Commission for Data Protection and Liberties (CNIL).

\section{Frailty definition}

Frailty was defined according to the construct derived from the Cardiovascular Health Study [1] adapted to declarative data. The five frailty dimensions were defined as follows:

- Exhaustion: self-reported physical fatigue or weakness or lack of energy;

- Unintentional weight loss of 5\% of body weight during the past 12 months;

- Muscle weakness: difficulty carrying a bag weighting $5 \mathrm{~kg}$ (in the absence of difficulty using hands or fingers) or difficulty bending of kneeling down without help;

- Impaired mobility: difficulty walking 500 meters without help or difficulty going up or down a dozen or more steps without help;

- Low level of physical activity: no practice of walk, bicycle or sport (jogging, fitness, swimming, biking, etc.).

Further details about the assessment of frailty (exact formulation of the question and coding) are given in Appendix 1. Frail individuals were those reporting three criteria or more. Previous work 
in ESPS 2012 showed consistency with other measures of the frailty phenotype in the general population [2], as in SHARE (the Survey of Health Ageing and Retirement in Europe) where objective measurements of gait speed and grip strength are available [18].

\section{Polypharmacy and potentially inappropriate medications}

The EGB contains exhaustive information on all the medications that were reimbursed to people during the year 2012. Medications are coded using the Anatomical Therapeutic Chemical (ATC) system. We estimated the number of medications used during the year 2012 by calculating the mean of the total number of medications used per 3-month periods. Polypharmacy was defined as five or more and excessive polypharmacy as 10 medications or more [7]. It included both regular and as required medications. PIMs were assessed over the whole year 2012 according to the Laroche list [19], which results from an expert consensus and takes into account drugs marketed in France. We excluded 5 criteria that required information about underlying conditions that could not be assessed here. Concomitant use of drugs corresponded to cases where two drugs were delivered on the same day. Based on current literature and national recommendations, we also considered inappropriate duration of treatment (3 reimbursements over a 4-month period) for some a priori selected drug classes, which were non-steroidal anti-inflammatory drugs [20] and benzodiazepines [20, 21], especially hypnotics [22].

\section{Other variables}

In addition to sociodemographic characteristics (age, gender, marital status, and education), information was collected about difficulties in doing alone 5 activities of daily living (ADL: 
eating, dressing and undressing, getting in and out of bed, using the toilets, bathing or showering) and 7 instrumental activities of daily living (IADL: food preparation, using the telephone, shopping, managing medications, light housekeeping, heavy housekeeping, managing finances and administrative tasks). Participants were asked about their body mass index, self-perceived health on a 5-point scale, social isolation, and tobacco smoking. Chronic diseases (over the last 12 months) were assessed among a standard list of 13 diseases including asthma, chronic bronchitis/emphysema, heart attack, stroke/cerebral haemorrhage, coronary disease/angina, high blood pressure, osteoarthritis, back pain, neck pain, diabetes, allergy, liver cirrhosis, and depression. Some diseases were grouped as follows:

- Respiratory diseases: asthma, chronic bronchitis/emphysema;

- Cardiovascular diseases: heart attack, stroke/cerebral haemorrhage, coronary disease/angina, high blood pressure;

- Musculoskeletal diseases: osteoarthritis, back pain, neck pain.

\section{Statistical analyses}

The statistical analysis describes sociodemographic and health variables, including frailty and medication use. We used individual sampling weights (the inverse of the probability that the observation is included considering sampling design, age, gender, household size, and social security scheme) to provide representative estimates.

Complete information about the five frailty criteria was available in $70.7 \%$ of the study population. In the remaining $29.3 \%$ cases, we imputed missing data regarding frailty criteria according to age and gender (logit modelling and imputation of the variable as 1 when the 
probability was more than $0.5,0$ otherwise). The proportion of frail individuals did not differ between the original and the imputed dataset $(\mathrm{p}=0.11)$. The prevalence of the original and imputed variables is given in the descriptive statistics.

The independent and combined effects of polypharmacy and PIMs on the progression of the frailty score from 0 to 5 were assessed by using Poisson regression models with the number of frailty criteria as the dependent variable. As first step of a multi-stage approach, we modelled the effect of polypharmacy and PIMs separately. Second, we adjusted the models for confounders, corresponding to the variables associated with the number of frailty criteria with a $p<0.20$. The final adjustment was obtained by progressively removing variables associated with frailty with a $\mathrm{p}>0.10$. Third, we entered simultaneously polypharmacy and PIMs, as well as confounders, in the model. Eventually, we added an interaction term between polypharmacy and PIMs. Results are presented in terms of Incidence Rate Ratios (IRR, i.e. exponentiated coefficients) with 95\% Confidence Interval $(95 \% \mathrm{CI})$.

Note that the analytical choices (imputation, use of sampling weights, Poisson modelling, and robust standard errors) aimed to maximise the statistical power of the analysis, which is of particular importance when introducing interaction terms in the models. Sensitivity analyses were conducted to test the influence of imputation on the frailty variables by repeating the analysis with the original variables. Analyses were performed by using Stata ${ }^{\circledR}$ version 14.

\section{Results}

Population 
The study population was composed of 1003 women and 887 men, of mean age $74.7+/-7.4$ years. They estimated their health good or very good in $39.7 \%$ of the cases. Musculoskeletal disorders were reported in more than half of the participants, followed by cardiovascular diseases, diabetes, and respiratory diseases. Frail people accounted for $16.4 \%$ of the study population, $14.8 \%$ when using the imputed variables. The characteristics of the study population are further described in table 1.

\section{Medication use}

Polypharmacy concerned $42.9 \%$ of the study population $(n=799)$, and excessive polypharmacy $27.4 \%(n=474)$. Potentially inappropriate prescribing according to the Laroche list concerned $36.8 \%$ of the study population $(n=664)$. When criteria assessing prolonged use of NSAIDs, benzodiazepines, and hypnotics were added, the prevalence of PIMs reached $46.7 \%(n=841)$. The most frequent PIMs involved benzodiazepines, anticholinergic drugs, NSAIDs, and cerebral vasodilators. Table 2 displays the frequency of the PIMs that concerned at least $1 \%$ of the study population. A complete description of the prevalence of PIMs is given in Appendix 2.

\section{Relationship between frailty, polypharmacy, and PIMs}

Models 1 and 2 of Table 3 show that both polypharmacy and inappropriateness of medications are associated with the number of frailty criteria in bivariate analysis. The Figure 1 illustrates the gradual increase in the prevalence of polypharmacy and PIMs with the number of frailty criteria. These associations remained significant after adjustment for confounders, including comorbidities in models 3 and 4 ( $\operatorname{IRR}_{5}$ to 9 drugs $=1.16,95 \% \mathrm{CI}[1.01-1.34]$; $\mathrm{IRR}_{10}$ drugs or more $=1.45$, 
95\%CI [1.25-1.69]; and $\mathrm{IRR}_{\mathrm{PIM}}=1.18,95 \% \mathrm{CI}$ [1.07-1.30]). When polypharmacy and PIMs were both introduced in the model (model 5), excessive polypharmacy only remained significantly associated with the number of frailty criteria. Several PIMs were specifically associated with the number of frailty criteria in bivariate analysis but the only one that remained significantly associated with the number of frailty criteria after the introduction of confounders and polypharmacy in the model was the prescription of anticholinergic drugs as defined in the Laroche list. There was no significant interaction between polypharmacy and PIMs, meaning that there was no indication to stratify the analyses on the level of polypharmacy.

\section{Sensitivity analyses}

We obtained similar results concerning the association of the number of frailty criteria with polypharmacy and PIMs when analyses were replicated using the non-imputed variables for frailty (see table in Appendix 3), though the association with the prescription of anticholinergic drugs hardly remained significant.

\section{$\underline{\text { Discussion }}$}

\section{Main findings}

By analysing the data from a nationally representative study matched with National Health Insurance data, this study provides insights about the prevalence of polypharmacy and PIMs and about their relationships with frailty in community-dwelling people aged 65 years and over. Polypharmacy and excessive polypharmacy were reported in $42.9 \%$ and $27.4 \%$ of the study population respectively, while $46.7 \%$ of the study population received at least one PIM, 
especially benzodiazepines, anticholinergic drugs, NSAIDs, and cerebral vasodilators. Polypharmacy and PIMs were both associated with the number of frailty criteria in models adjusted for socio-demographic and health characteristics of the individuals. The prescription of anticholinergic medications was the only PIM that remained significantly associated with the number of frailty criteria after adjustment for polypharmacy.

\section{Prevalence of polypharmacy and PIMs}

Our estimates of the prevalence of polypharmacy and PIMs are relatively high compared to previous estimates $[7,9,11,23]$, which was expected considering our methodology. Indeed, the prevalence of polypharmacy should be considered with regard to our definition that encompasses all the medications prescribed over 3-month periods. Considering PIMs, their prevalence was assessed over an entire year and not at a given time point, which obviously increased the chance of having one PIM for a given subject compared to a punctual assessment. Moreover, we added 3 criteria (assessing potentially inappropriate prolonged use of medications) to those of the Laroche list, which happened to increase by nearly $10 \%$ the prevalence of PIMs. Consistently with the review by Tommelein et al [23], we found benzodiazepines and NSAIDs among the most reported PIMs. Conversely, inappropriate use of antidepressants was limited in our study.

\section{PIMs and frailty}

The relationship between PIMs and frailty initially observed in unadjusted and partially adjusted models became non-significant when polypharmacy was introduced in the multivariate models. This result suggests that the association between PIMs and frailty reflects the association between 
PIMs and polypharmacy in the one hand and between polypharmacy and frailty in the other hand. Nevertheless, this result should be considered with caution because PIMs still tended to be associated with frailty in the model adjusted for polypharmacy and we cannot exclude a lack of power to detect a significant association. Collinearity between polypharmacy and PIMs may have increased estimates of parameter variance, hence reducing the likelihood of showing a significant association between PIMs and frailty. Nevertheless, this hypothesis is unlikely regarding the results of diagnostic tests for colinearity between polypharmacy and PIMs; both the Variance Inflation Factor (VIF) and the condition number were inferior to admitted thresholds (VIF=1.21 $<10$ and condition number $<15)$ [24]. Besides, PIMs include heterogeneous situations in terms of risk. Some medications are said inappropriate because of their safety profile, whereas others are said inappropriate because of uncertainty about their efficacy. That is why we considered PIMs altogether and by criteria. Doing this, we actually showed a significant association between frailty and anticholinergic medications that persisted after adjustment for polypharmacy.

\section{Polypharmacy, anticholinergic medications, and frailty}

Our results confirm the previously reported association between excessive polypharmacy and frailty [7], and extend to the general population the results of Moulis et al [25] who showed that medications with anticholinergic properties were associated with frailty in people attending a frailty clinic in France, after adjustment for polypharmacy. Anticholinergic medications can cause peripheral (dry mouth and constipation) and central (falls, dizziness, delirium, and cognitive decline) adverse effects [26] that could participate in the development of frailty through altered nutritional intake, limitation of mobility or cognitive impairment. Gnjidic et al [27] suggested the potential contribution of medicines to the development of frailty, consistently with 
the results of previous studies showing an increased risk of incident frailty in people with polypharmacy $[9,28]$.

\section{Strength and limitations}

The strength of this study is that we used a unique dataset combining a nationally representative health survey with respondents' National Health Insurance data on medication reimbursements. Nevertheless, this study has limitations. Though nationally representative, we had a limited sample of people aged 65 years and over. Concerning the assessment of frailty, we used selfreported variables in the absence of objective measures of grip strength and walking speed. Another limitation is that $29.7 \%$ had missing data regarding one or more frailty variable. Considering only people with complete information would have led to a selection bias and a loss of power, which is why we imputed missing data based on available information. Results were similar with regard to the estimated coefficients but differed somehow with regard to the standard error of the estimates. The lack of statistical power was substantial in the case of the sample with non-missing observation. However, imputation of frailty criteria conditional on age and sex helped improve the statistical power without introducing bias in the estimates because (i) age and sex are exogenous covariates (not determined by frailty or its determinants) and (ii) these two variables are included as covariates in the model, thus assigning the observations to the average individual. Though highly reliable, data about medication use only reflect medication bought by people and not those actually taken. In the case of concomitant use, defined as situations where two drugs of the same class were delivered on the same day, we miss cases where people buy their medications on different days and use medications they have left at home. Furthermore, we did not have information about the use of over-the-counter products and medications received during hospitalisation. Eventually, the 
cross-sectional design of this study did not enable to conclude on the causality of the relationships between frailty, polypharmacy and PIMs.

\section{$\underline{\text { Conclusion }}$}

This study shows that polypharmacy and use of anticholinergic medications are independently associated with frailty in old people. This should increase awareness towards the overuse of medications in old people and should encourage physicians to supress the prescriptions that are known to have a poor benefit-risk ratio in their patients, especially anticholinergic medications. Longitudinal studies are required to establish the respective role of polypharmacy and PIMs on the development of frailty.

\section{$\underline{\text { References }}$}

1 Fried LP, Tangen CM, Walston J, Newman AB, Hirsch C, Gottdiener J, Seeman T, Tracy R, Kop WJ, Burke G, McBurnie MA (2001) Frailty in older adults: evidence for a phenotype. J Gerontol A Biol Sci Med Sci 56 (3): M146-156

2 Sirven N, Rapp T (2016) The cost of frailty in France. The European journal of health economics : HEPAC : health economics in prevention and care DOI 10.1007/s10198-016-0772-7

3 Sirven N, Rapp T (2016) The Dynamics of Hospital Use among Older People Evidence for Europe Using SHARE Data. Health services research DOI 10.1111/1475-6773.12518

4 Bergman H, Ferrucci L, Guralnik J, Hogan DB, Hummel S, Karunananthan S, Wolfson C (2007) Frailty: an emerging research and clinical paradigm--issues and controversies. J Gerontol A Biol Sci Med Sci 62 (7): 731-737 DOI 62/7/731 [pii] 
5 Shamliyan T, Talley KM, Ramakrishnan R, Kane RL (2013) Association of frailty with survival: a systematic literature review. Ageing research reviews 12 (2): 719-736 DOI 10.1016/j.arr.2012.03.001

6 Morley JE, Vellas B, van Kan GA, Anker SD, Bauer JM, Bernabei R, Cesari M, Chumlea WC, Doehner W, Evans J, Fried LP, Guralnik JM, Katz PR, Malmstrom TK, McCarter RJ, Gutierrez Robledo LM, Rockwood K, von Haehling S, Vandewoude MF, Walston J (2013) Frailty consensus: a call to action. Journal of the American Medical Directors Association 14 (6): 392 397 DOI 10.1016/j.jamda.2013.03.022

7 Herr M, Robine JM, Pinot J, Arvieu JJ, Ankri J (2015) Polypharmacy and frailty: prevalence, relationship, and impact on mortality in a French sample of 2350 old people. Pharmacoepidemiology and drug safety 24 (6): 637-646 DOI 10.1002/pds.3772

8 Chang CI, Chan DC, Kuo KN, Hsiung CA, Chen CY (2011) Prevalence and correlates of geriatric frailty in a northern Taiwan community. J Formos Med Assoc 110 (4): 247-257 DOI S09296646(11)60037-5 [pii]

10.1016/S0929-6646(11)60037-5

9 Gnjidic D, Hilmer SN, Blyth FM, Naganathan V, Cumming RG, Handelsman DJ, McLachlan AJ, Abernethy DR, Banks E, Le Couteur DG (2012) High-risk prescribing and incidence of frailty among older community-dwelling men. Clin Pharmacol Ther 91 (3): 521-528 DOI clpt2011258 [pii]

$10.1038 /$ clpt.2011.258

10 Rosted E, Schultz M, Sanders S (2016) Frailty and polypharmacy in elderly patients are associated with a high readmission risk. Danish medical journal 63 (9)

11 Saum KU, Schottker B, Meid AD, Holleczek B, Haefeli WE, Hauer K, Brenner H (2017) Is Polypharmacy Associated with Frailty in Older People? Results From the ESTHER Cohort Study. J Am Geriatr Soc 65 (2): e27-e32 DOI 10.1111/jgs.14718 
12 Fried TR, O'Leary J, Towle V, Goldstein MK, Trentalange M, Martin DK (2014) Health outcomes associated with polypharmacy in community-dwelling older adults: a systematic review. J Am Geriatr Soc 62 (12): 2261-2272 DOI 10.1111/jgs.13153

13 Frazier SC (2005) Health outcomes and polypharmacy in elderly individuals: an integrated literature review. Journal of gerontological nursing 31 (9): 4-11

14 Lai SW, Liao KF, Liao CC, Muo CH, Liu CS, Sung FC (2010) Polypharmacy correlates with increased risk for hip fracture in the elderly: a population-based study. Medicine 89 (5): 295-299 DOI 10.1097/MD.0b013e3181f15efc

15 Gnjidic D, Hilmer SN, Blyth FM, Naganathan V, Waite L, Seibel MJ, McLachlan AJ, Cumming RG, Handelsman DJ, Le Couteur DG (2012) Polypharmacy cutoff and outcomes: five or more medicines were used to identify community-dwelling older men at risk of different adverse outcomes. J Clin Epidemiol 65 (9): 989-995 DOI S0895-4356(12)00084-4 [pii]

10.1016/j.jclinepi.2012.02.018

16 Beer C, Hyde Z, Almeida OP, Norman P, Hankey GJ, Yeap BB, Flicker L (2011) Quality use of medicines and health outcomes among a cohort of community dwelling older men: an observational study. Br J Clin Pharmacol 71 (4): 592-599 DOI 10.1111/j.1365-2125.2010.03875.x

17 Beers MH, Ouslander JG, Fingold SF, Morgenstern H, Reuben DB, Rogers W, Zeffren MJ, Beck JC (1992) Inappropriate medication prescribing in skilled-nursing facilities. Annals of internal medicine 117 (8): 684-689

18 Célant N, Guillaume S, Rochereau T (2014) Enquête sur la santé et la protection sociale 2012. Les rapports de l'IRDES n ${ }^{\circ} 556$. In: ed.

19 Laroche ML, Charmes JP, Merle L (2007) Potentially inappropriate medications in the elderly: a French consensus panel list. Eur J Clin Pharmacol 63 (8): 725-731 DOI 10.1007/s00228-007$0324-2$ 

V, Sciortino V, Bouvenot G, Verger P (2012) [Potentially inappropriate prescriptions for the elderly: a study of health insurance reimbursements in Southeastern France]. Revue d'epidemiologie et de sante publique 60 (2): 121-130 DOI 10.1016/j.respe.2011.10.004

21 Rémunération sur objectif de santé publique (ROSP) concernant les Benzodiazépines. L'Assurance Maladie. In: ed.

22 (2012) The American Geriatrics Society 2012 Beers Criteria Update Expert Panel. American Geriatrics Society Updated Beers Criteria for Potentially Inappropriate Medication Use in Older Adults. J Am Geriatr Soc 60: 616-631

23 Tommelein E, Mehuys E, Petrovic M, Somers A, Colin P, Boussery K (2015) Potentially inappropriate prescribing in community-dwelling older people across Europe: a systematic literature review. Eur J Clin Pharmacol 71 (12): 1415-1427 DOI 10.1007/s00228-015-1954-4

24 Dormann CF, Elith J, Bacher S, Buchmann C, Carl G, Carre G, Marquez JRG, Gruber B, Lafourcade B, Leitao PJ, Munkemuller T, McClean C, Osborne PE, Reineking B, Schroder B, Skidmore AK, Zurell D, Lautenbach S (2013) Collinearity: a review of methods to deal with it and a simulation study evaluating their performance. Ecography 36 (1): 27-46 DOI 10.1111/j.1600-0587.2012.07348.x

25 Moulis F, Moulis G, Balardy L, Gerard S, Montastruc F, Sourdet S, Rouge-Bugat ME, LapeyreMestre M, Montastruc JL, Rolland Y, Vellas B (2015) Exposure to atropinic drugs and frailty status. Journal of the American Medical Directors Association 16 (3): 253-257 DOI 10.1016/j.jamda.2014.11.017

26 Gerretsen P, Pollock BG (2011) Drugs with anticholinergic properties: a current perspective on use and safety. Expert opinion on drug safety 10 (5): 751-765 DOI $10.1517 / 14740338.2011 .579899$

27 Gnjidic D, Hilmer SN (2012) Potential contribution of medications to frailty. J Am Geriatr Soc 60 (2): 401 DOI 10.1111/j.1532-5415.2011.03810.x 
28 Wang R, Chen L, Fan L, Gao D, Liang Z, He J, Gong W, Gao L (2015) Incidence and Effects of Polypharmacy on Clinical Outcome among Patients Aged 80+: A Five-Year Follow-Up Study. PloS one 10 (11): e0142123 DOI 10.1371/journal.pone.0142123 
Table 1. Characteristics of the people aged 65+ included in ESPS $2012(\mathrm{~N}=1890)$

\begin{tabular}{|c|c|c|}
\hline Variable & $\mathbf{N}$ & Prevalence $(\%)$ \\
\hline \multicolumn{3}{|l|}{ Age (years) } \\
\hline $65-69$ & 616 & 26.1 \\
\hline $70-74$ & 386 & 17.2 \\
\hline $75-79$ & 389 & 18.2 \\
\hline $80-84$ & 273 & 20.5 \\
\hline $85+$ & 226 & 17.9 \\
\hline \multicolumn{3}{|l|}{ Gender } \\
\hline Male & 887 & 39.5 \\
\hline Female & 1003 & 60.5 \\
\hline Married / living as a couple & 1253 & 94.9 \\
\hline \multicolumn{3}{|l|}{ Education } \\
\hline No diploma & 443 & 23.9 \\
\hline$<$ A-level & 1057 & 56.8 \\
\hline A-level & 158 & 8.4 \\
\hline$>$ A-level & 209 & 9.5 \\
\hline Other & 23 & 1.3 \\
\hline \multicolumn{3}{|l|}{ Difficulty in activities of daily living } \\
\hline No & 812 & 44.7 \\
\hline In $\geq 1$ IADL, but not in ADL & 541 & 34.3 \\
\hline $\mathrm{In} \geq 1 \mathrm{ADL}$ & 311 & 21.1 \\
\hline \multicolumn{3}{|l|}{ BMI } \\
\hline$<18.5 \mathrm{~kg} / \mathrm{m}^{2}$ & 36 & 2.5 \\
\hline$\geq 18.5$ et $<25 \mathrm{~kg} / \mathrm{m}^{2}$ & 643 & 41.9 \\
\hline$\geq 25$ et $<30 \mathrm{~kg} / \mathrm{m}^{2}$ & 630 & 36.6 \\
\hline$\geq 30 \mathrm{~kg} / \mathrm{m}^{2}$ & 316 & 19.1 \\
\hline \multicolumn{3}{|l|}{ Tobacco smoking } \\
\hline Never & 1066 & 67.6 \\
\hline
\end{tabular}




\begin{tabular}{|c|c|c|}
\hline Yes, in the past & 428 & 24.3 \\
\hline Yes, currently & 140 & 8.1 \\
\hline $\begin{array}{l}\text { Social isolation during at least one period of } \\
\text { life }\end{array}$ & 233 & 15.7 \\
\hline \multicolumn{3}{|l|}{ Self-perceived health } \\
\hline Good or very good & 681 & 39.7 \\
\hline Fair & 676 & 40.9 \\
\hline Poor or very poor & 291 & 19.4 \\
\hline \multicolumn{3}{|l|}{ Chronic diseases } \\
\hline Musculoskeletal & 849 & 54.6 \\
\hline Cardiovascular & 575 & 36.8 \\
\hline Diabetes & 278 & 17.2 \\
\hline Respiratory & 259 & 16.6 \\
\hline Allergy & 209 & 13.0 \\
\hline Depression & 110 & 7.4 \\
\hline Liver & 6 & 0.0 \\
\hline \multicolumn{3}{|l|}{ Frailty criteria (original / imputed) } \\
\hline Exhaustion & $561 / 563$ & $35.1 / 30.3$ \\
\hline Unintentional weight loss & $175 / 175$ & $11.2 / 9.8$ \\
\hline Muscle weakness & $443 / 471$ & $32.7 / 31.0$ \\
\hline Impaired mobility & $258 / 261$ & $19.5 / 17.3$ \\
\hline Low level of physical activity & $312 / 316$ & $23.5 / 18.5$ \\
\hline \multicolumn{3}{|l|}{ Number of frailty criteria (original / imputed) } \\
\hline 0 & $544 / 873$ & $37.1 / 42.1$ \\
\hline 1 & 417 / 561 & $30.4 / 29.2$ \\
\hline 2 & $191 / 229$ & $16.1 / 13.9$ \\
\hline 3 & $118 / 148$ & $10.3 / 9.7$ \\
\hline 4 & $60 / 71$ & $5.6 / 4.8$ \\
\hline 5 & $8 / 8$ & $0.5 / 0.4$ \\
\hline
\end{tabular}

Note: prevalence takes into account sampling weights. 
Table 2. Potentially inappropriate medications received by $1 \%$ or more of the participants aged 65+ in ESPS $2012(\mathrm{~N}=1890)$

\begin{tabular}{|c|c|c|c|}
\hline Potentially inappropriate medications & ATC & $\mathbf{N}$ & $\begin{array}{c}\text { Prevalence } \\
\text { (\%) }\end{array}$ \\
\hline \multicolumn{4}{|l|}{ Laroche list criteria $^{a}$} \\
\hline Non-steroidal anti-inflammatory drugs & & 74 & 3.9 \\
\hline \multicolumn{4}{|l|}{ (NSAIDs) } \\
\hline$\geq 2$ NSAIDs & M01A & 72 & 3.8 \\
\hline Anticholinergic drugs & & 161 & 9.2 \\
\hline Tricyclic antidepressant & & 47 & 2.4 \\
\hline Amitriptyline & N06AA09 & 31 & 1.8 \\
\hline Antihistamins $\mathrm{H} 1$ & & 79 & 4.7 \\
\hline Hydroxyzine & N05BB01 & 69 & 4.0 \\
\hline Anticholinergic urinary & & 28 & 1.7 \\
\hline \multicolumn{4}{|l|}{ antispasmodics } \\
\hline Solifenacine & G04BD08 & 28 & 1.5 \\
\hline Long-acting benzodiazepines & & 232 & 12.6 \\
\hline Bromazepam & N05BA08 & 138 & 7.7 \\
\hline Prazepam & N05BA11 & 45 & 2.5 \\
\hline Clonazepam & N03AE01 & 25 & 1.2 \\
\hline Antihyperthensives & & 98 & 6.2 \\
\hline Centrally acting & & 60 & 4.0 \\
\hline Rilmenidine & $\mathrm{C} 02 \mathrm{AC} 06$ & 51 & 3.4 \\
\hline Short-acting calcium-channel & & 42 & 2.4 \\
\hline \multicolumn{4}{|l|}{ blockers } \\
\hline Nicardipine & C08CA04 & 35 & 1.9 \\
\hline
\end{tabular}


ATC

$\mathbf{N}$

Prevalence

(\%)

Cerebral vasodilators

Ginkgo

Naftidrofuryl

Piribedil

Other drugs with anticholinergic properties and questionable efficacy

Oxomemazine

Metopimazine

Antimicrobial

Nitrofurantoïne

Concomitant dispensation of psychotropic

drugs of the same the same class

Concomitant dispensation of 2

benzodiazepines

\section{Additional criteria}

Prolonged use of hypnotics $(\geq 3$

reimbursements over a 4-month period) ${ }^{b}$

Prolonged use of benzodiazepines $(\geq 3$

reimbursements over a 4 -month period) ${ }^{c}$
R06AD08

A04AD05

J01XE01

N05BA

N05CD

$\mathrm{N} 05 \mathrm{CF}$

N03AE01

M03BX07

N05CF01

123

7.4

144

8.5

71

4.5

35

1.7

23

1.3

139

7.2

77

3.6

54

3.4

17

1.0

17

1.0

34

2.0

28

1.7

N05CF02

N05BA

338

19.9
N05CD

N05CF

N03AE01

M03BX07 
Potentially inappropriate medications

Potentially inappropriate medications

\section{ATC}

M01A

Prolonged use of NSAIDs $(\geq 3$

reimbursements over a $4-$ month period) ${ }^{\mathrm{c}}$

At least one PIM of the Laroche list

At least one PIM of the Laroche list + other

criteria

Note: Prevalence takes into account sample weights.
$\mathbf{N}$

664

841

Prevalence

(\%)

211

11.3

36.8

46.7 
Table 3. Poisson regression models of the number of frailty criteria according to medications among participants aged $65+$ in ESPS 2012

$(\mathrm{N}=1542)$

\begin{tabular}{|c|c|c|c|c|c|c|}
\hline & Model 1 & Model 2 & Model 3 & Model 4 & Model 5 & Model 6 \\
\hline \multicolumn{7}{|l|}{ Polypharmacy } \\
\hline $5-9$ versus $0-4$ drugs & $1.587 * * *$ & & $1.163 * *$ & & $1.139 *$ & $1.171^{*}$ \\
\hline $10+$ versus $0-4$ drugs & $2.710 * * *$ & & $1.451 * * *$ & & $1.392 * * *$ & $1.501 * * *$ \\
\hline \multicolumn{7}{|l|}{ PIMs } \\
\hline At least one PIM of the Laroche list + other criteria & & $1.578 * * *$ & & $1.180 * * *$ & $1.102 *$ & $1.221 *$ \\
\hline Anticholinergic drugs & & $1.521 * * *$ & & $1.192 * *$ & $1.169^{* *}$ & $1.337 * *$ \\
\hline Long-acting benzodiazepines & & $1.266^{* *}$ & & 1.072 & 1.012 & 1.062 \\
\hline Antihyperthensives & & $1.384 * *$ & & 0.967 & 0.958 & 1.018 \\
\hline Cerebral vasodilators & & $1.211 * *$ & & 1.085 & 1.015 & 1.201 \\
\hline Concomitant dispensation of psychotropic drugs of the & & $1.454 * *$ & & 1.110 & 1.093 & 1.093 \\
\hline same class & & & & & & \\
\hline $\begin{array}{l}\text { Prolonged use of hypnotics ( } \geq 3 \text { reimbursements over a } 4 \text { - } \\
\text { month period) })^{b}\end{array}$ & & $1.454 * * *$ & & 1.095 & 1.007 & 1.190 \\
\hline Prolonged use of benzodiazepines ( $\geq 3$ reimbursements & & $1.556^{* * *}$ & & $1.112 * *$ & 1.034 & 1.201 \\
\hline over a 4-month period) $)^{\mathrm{c}}$ & & & & & & \\
\hline $\begin{array}{l}\text { Prolonged use of NSAIDs ( } \geq 3 \text { reimbursements over a 4- } \\
\text { month period) })^{c}\end{array}$ & & $1.165^{*}$ & & $1.166^{* *}$ & 1.106 & 0.807 \\
\hline
\end{tabular}


Values are Incidence Rate Ratio (IRR)

$* p<.1 ; * * p<.05 ; * * * p<.001$

Model 1: number of frailty criteria polypharmacy

Model 2: number of frailty criteria $\sim$ PIMs

Model 3: number of frailty criteria polypharmacy + confounders

Model 4: number of frailty criteria $\sim$ PIMs + confounders

Model 5: number of frailty criteria $\sim$ polypharmacy + PIMs + confounders

Model 6: number of frailty criteria polypharmacy + PIMs + interaction term + confounders

Confounders: age, gender, difficulties in activities of daily living, self-perceived heath, cardiovascular diseases, musculoskeletal diseases, diabetes, depression, and BMI 
Figure 1. Prevalence of polypharmacy and PIMs according to the number of frailty criteria $(\mathrm{N}=1890)$ 